\title{
Characterization of the volatile fraction emitted by phloems of four pinus species by solid-phase microextraction and gas chromatography-mass spectrometry
}

\author{
A.M. Santos ${ }^{\text {a }}$, T. Vasconcelos ${ }^{\text {b }}$, E. Mateus ${ }^{\text {a }}$, M.H. Farrall ${ }^{\text {a }}$, \\ M.D.R. Gomes da Silva ${ }^{c}$, M.R. Paiva ${ }^{a}, *$ M. Branco ${ }^{\mathrm{d}, *}$ \\ ${ }^{a}$ GUECKO/Departamento de Ciências e Engenharia do Ambiente, FCT, Universidade Nova de Lisboa 2829-516 Campus de Caparica, Portugal \\ ${ }^{\mathrm{b}}$ Departamento de Ciências Exactas e do Ambiente, Escola Superior Agrária de Coimbra, 3040-316 Bencanta, Coimbra, Portugal \\ ${ }^{\mathrm{c}}$ REQUIMTE, Departamento de Química, FCT-UNL, 2829-516, Caparica, Portugal \\ ${ }^{\mathrm{d}}$ DEF/Departamento de Engenharia Florestal, Instituto Superior de Agronomia, Universidade Técnica de Lisboa, \\ Tapada da Ajuda, 1349-17 Lisboa, Portugal
}

Available online 23 November 2005

\begin{abstract}
Pine forests constitute some of the most important renewable resources supplying timber, paper and chemical industries, among other functions. Characterization of the volatiles emitted by different Pinus species has proven to be an important tool to decode the process of host tree selection by herbivore insects, some of which cause serious economic damage to pines. Variations in the relative composition of the bouquet of semiochemicals are responsible for the outcome of different biological processes, such as mate finding, egg-laying site recognition and host selection. The volatiles present in phloem samples of four pine species, $P$. halepensis, $P$. sylvestris, $P$. pinaster and $P$. pinea, were identified and characterized with the aim of finding possible host-plant attractants for native pests, such as the bark beetle Tomicus piniperda. The volatile compounds emitted by phloem samples of pines were extracted by headspace solid-phase micro extraction, using a $2 \mathrm{~cm} 50 / 30 \mathrm{~mm}$ divinylbenzene/carboxen/polydimethylsiloxane table flex solid-phase microextraction fiber and its contents analyzed by high-resolution gas chromatography, using flame ionization and a non polar and chiral column phases. The components of the volatile fraction emitted by the phloem samples were identified by mass spectrometry using time-of-flight and quadrupole mass analyzers. The estimated relative composition was used to perform a discriminant analysis among pine species, by means of cluster and principal component analysis. It can be concluded that it is possible to discriminate pine species based on the monoterpenes emissions of phloem samples.
\end{abstract}

(C) 2005 Published by Elsevier B.V.

Keywords: Tomicus spp.; Pinus spp.; Monoterpenes; SPME; GC-FID; GC-TOF-MS

\section{Introduction}

Bark beetles constitute some of the economically most important insects for pine forests [1], since epidemic levels are often reached, particularly after fires and storms, killing healthy trees and causing serious damage to stands. Tomicus piniperda is an endemic species able of colonizing weakened, stressed or recently killed trees [1]. The larvae excavate galleries in the phloem of the trunks and of freshly cut logs, while adults must feed on shoots to complete sexual maturation [1-4]. T. piniperda

\footnotetext{
* Corresponding authors.

E-mail addresses: mrp@fct.unl.pt (M.R. Paiva),mrb@isa.utl.pt (M. Branco).
}

is a monogamous species which have no known pheromones to either attract mates or locate breeding sites [5]. Host selection is achieved by detection of the monoterpenes released by the trees, which act as kairomones [2-6].

Monoterpenes are a group of volatile plant secondary metabolism compounds, that act as primary defence against pathogenic agents and are thought to be a key tool to decode insect-host interactions [6-15]. Several authors have referred that both biosynthesis and biogenesis of mono- and sesquiterpenes are genetic and species dependent $[12,16]$. The differences found in the emission patterns of the genus Pinus are reported to be mainly quantitative, allowing for interspecific discrimination $[9-12,15]$. The importance of specifying the type of tissue sample used in the analysis has also been pointed out, since variations in the relative amount of the constituents, 
as well as the enantiomeric composition of the monoterpenes were observed, both between and within conifer species $[9,12,17]$.

Most studies on conifer monoterpene emissions used samples from foliage [8,9,11,16,18-22], cortex tissue [12], seeds [10], cones [11], or bark volatiles emissions after insect oviposition induction $[14,15]$. In most of these studies, simultaneous destillation-extraction (SDE) methods were used to isolate the volatile compounds from the complex matrices $[8,9,13,20,23,24]$. However, the presence of the extraction solvent that frequently coelutes, during the chromatographic run, with less retained peaks, is an important drawback of this technique [22]. Headspace solid-phase microextraction (HS-SPME) has the isolation capability of SDE while allowing for the isolation to be achieved without solvent intervention. Moreover, the wide variety of fibers that can be used, depending on the functionalities of the target organic compounds, made it a simple, quick, sensitive and versatile method of sample preparation, suitable for routine analysis of monoterpenes in tree tissue [10-12,14-16,22,23].

Within the genus Pinus, phylogenetic relationships have been established mostly based on pine morphological characteristics, such as needles and cones, as well as on the species geographic distribution [25], while DNA markers, proteins and terpenes have been used to corroborate the taxonomic distinctions found among species [26-28]. Further studies showed that it is possible to differentiate Pinus genus using the volatile terpene composition of pine needles $[8-11,13,16]$ and similar results were found for the genus Tsuga [29]. In this study, we investigated whether volatile terpene emissions from the phloem of pine trunks, might also be used as a distinguishing character among coniferous species. Therefore, we characterized the volatile fraction emitted by trunk phloem sections of four pine species, $P$. pinaster, $P$. sylvestris, $P$. pinea and $P$. halepensis, by means of headspace solid-phase microextraction (SPME), gas chromatography (GC) and mass spectrometry (GC-MS), as a potential method to be used for the determination of pine species.

Hierarchical cluster analysis was used to study the chemical variability of the four Pinus species analyzed. Principal component (PC) analysis was applied to study the nature and magnitude of the differentiation among species.

\section{Materials and methods}

\subsection{Standards}

All monoterpene standards used were purchased from Aldrich (Deisenhofen, Germany), Fluka (Neu-Ulm, Germany) and Kasei (Tokyo, Japan).

\subsection{Research materials}

Phloems were sampled from $P$. halepensis, $P$. sylvestris, $P$. pinaster and $P$. pinea, in October 2004, from stands located in central Portugal (Table 1). After collection samples were stored immediately in liquid nitrogen until the analysis were performed.
Table 1

Sampling locations, in Portugal, October 2004

\begin{tabular}{llll}
\hline Species & Sampling site & Latitude & Longitude \\
\hline P. pinaster & Serra da Lousã & $40^{\circ} 08^{\prime} \mathrm{N}$ & $8^{\circ} 10^{\prime} \mathrm{W}$ \\
$P$. sylvestris & Serra da Lousã & $40^{\circ} 08^{\prime} \mathrm{N}$ & $8^{\circ} 10^{\prime} \mathrm{W}$ \\
$P$. pinea & Alcácer do Sal & $38^{\circ} 23^{\prime} \mathrm{N}$ & $8^{\circ} 31^{\prime} \mathrm{W}$ \\
$P$. halepensis & Serra da Ota & $39^{\circ} 07^{\prime} \mathrm{N}$ & $8^{\circ} 59^{\prime} \mathrm{W}$ \\
\hline
\end{tabular}

\subsection{Sample preparation}

All phloem samples were weighted, cut and transferred to a $7.0 \mathrm{ml}$ sealed vial (Supelco, Bellefonte, USA). Their volatile fraction was extracted by solid-phase microextraction using a $100 \mu \mathrm{m}$ polydimethylsiloxane (PDMS) coated fiber for enantiomeric separation, and a 50/30 $\mu \mathrm{m}$ divinylbenzene/Carboxen/polydimethylsiloxane (DVB/CAR/PDMS) coated fiber (both from Supelco, Belfonte, USA) for nonenantiomeric separation. The headspace extraction was performed at room temperature for $60 \mathrm{~min}$ and the trapped compounds desorbed at $250^{\circ} \mathrm{C}$ in the injection port, for $60 \mathrm{~s}$. Before the analysis, the fibers were conditioned according to the manufacturer standard procedures.

\subsection{Analysis of monoterpenes}

\subsubsection{GC-FID analysis}

The analysis of the volatile compounds was performed by gas chromatography, using a HP 5890A gas chromatograph (Hewlett Packard, USA) equipped with flame ionization detection (GCFID). The separation was achieved on a DB-5 capillary column with $30 \mathrm{~m} \times 0.32 \mathrm{~mm}$ I.D., $1.0 \mu \mathrm{m}$ thickness (J \&W Scientific, Folsom, USA) after split injection (1:20), using hydrogen as carrier gas, at flow rate of $1.7 \mathrm{ml} / \mathrm{min}$.

Oven temperature was initially held at $50{ }^{\circ} \mathrm{C}$ for $1 \mathrm{~min}$ and increased up to $125^{\circ} \mathrm{C}$, at a rate of $4^{\circ} \mathrm{C} / \mathrm{min}$. From $125^{\circ} \mathrm{C}$, it was further increased up to $250{ }^{\circ} \mathrm{C}$ at $6{ }^{\circ} \mathrm{C} / \mathrm{min}$ rate where it was held for $5 \mathrm{~min}$. The final temperature of $295^{\circ} \mathrm{C}$ was reached at a rate of $10^{\circ} \mathrm{C} / \mathrm{min}$. The flame ionization detector temperature was set at $300^{\circ} \mathrm{C}$.

\subsubsection{Enantiomeric analysis}

The separation of enantiomeric monoterpenes was performed on a taylor made fused silica capillary column with $30 \mathrm{~m} \times 0.25 \mathrm{~mm}$ I.D., coated with $0.25 \mu \mathrm{m}$ film of $15 \%$ heptakis (2,3-di- $O$-methyl-6-O-terc-butyldimethylsilyl)$\beta$-cyclodextrin in SE52 (DiMe). The column was placed on a GC-Trace 2000 (Thermo Unicam, USA) equipped with flame ionization detection. Hydrogen was used as carrier gas, with a flow rate of $1.0 \mathrm{ml} / \mathrm{min}$. The oven temperature was initially set at $68^{\circ} \mathrm{C}$ and kept isothermal for $15 \mathrm{~min}$. Afterwards, it was increased at a rate of $2{ }^{\circ} \mathrm{C} / \mathrm{min}$ until $125^{\circ} \mathrm{C}$, followed by a rate of $5^{\circ} \mathrm{C} / \mathrm{min}$ to $200{ }^{\circ} \mathrm{C}$ where it was held for $1 \mathrm{~min}$. The flame ionization detector temperature was set at $250{ }^{\circ} \mathrm{C}$. All compounds were detected by standard co-injection. 


\subsubsection{GC-TOF-MS analysis}

The GC-MS analysis were carried out on an Agilent 6890N gas chromatograph, coupled to a mass spectrometer Micromass GCT (Manchester, UK) equipped with a time-of-flight (TOF) mass analyzer. Separation was performed on a $30 \mathrm{~m} \times 0.25 \mathrm{~mm}$ I.D., $0.25 \mu \mathrm{m}$ thickness fused silica ZB-5ms column (Phenomenex, Torrance, USA). Sample injection was performed with a split ratio of 1:20. Helium was used as carrier gas with a flow rate of $0.8 \mathrm{ml} / \mathrm{min}$.

The mass spectrometer operated in electron impact mode $(70 \mathrm{eV})$ with a mass range set from 35 to $350 \mathrm{~m} / \mathrm{z}$. The interface and source temperatures were set at $250{ }^{\circ} \mathrm{C}$ and gas chromatography conditions were as given.

\subsection{Data analysis}

\subsubsection{Peak identification}

Individual peaks of compounds were detected by comparison with retention times of standard pure solutions under similar operating conditions. The compounds were identified by comparing the mass spectra obtained for the standards and by Wiley 7 th mass spectral reference library.

\subsubsection{Statistical analysis}

Relative area percentage of the monoterpenes present in the volatile fraction was used for data analysis. Data processing was performed using SPSS (V.12 for Windows) statistical package.

Pine species homogeneity was analyzed by hierarchical cluster analysis using Ward's method and square Euclidean distances, based on the content of the monoterpenes emitted by phloem samples, which were variables impossible to normalize. Principal component analysis was used to determine the key enantiomers that best explain the species sets. Enantiomers relative percentages were transformed (cubic root) and standardized to obtain normal distributed variables.

\section{Results and discussion}

The chromatogram profiles for non-chiral and chiral analysis of the volatile fractions present in the phloem samples are exemplified, respectively, in Figs. 1 and 2.

We identified 11 monoterpenes (Figs. 1 and 2; Tables 2 and 3), that have been previously reported to play a role in the process of host tree selection by conifers phytophagous insects [1,2,4-11,15,17-20]. Traces of non-terpenoid volatiles, such as 4-methyl-hex-4-en-3-one, oct-1-en-3-ol and benzaldehyde were also identified, although not used for data treatment. The volatile compositions estimated for the species sampled are shown on Table 2. Fig. 3 represents the dendrogram obtained through a hierarchical cluster analysis, using Ward's method. $P$. pinea appears as the most homogeneous group, while $P$. halepensis shows larger heterogeneity, with two groups of samples clearly identifiable. $P$. sylvestris and $P$. pinaster are separated in the dendogram at species level. Nevertheless, these two species are grouped together in one of the three main clusters obtained.

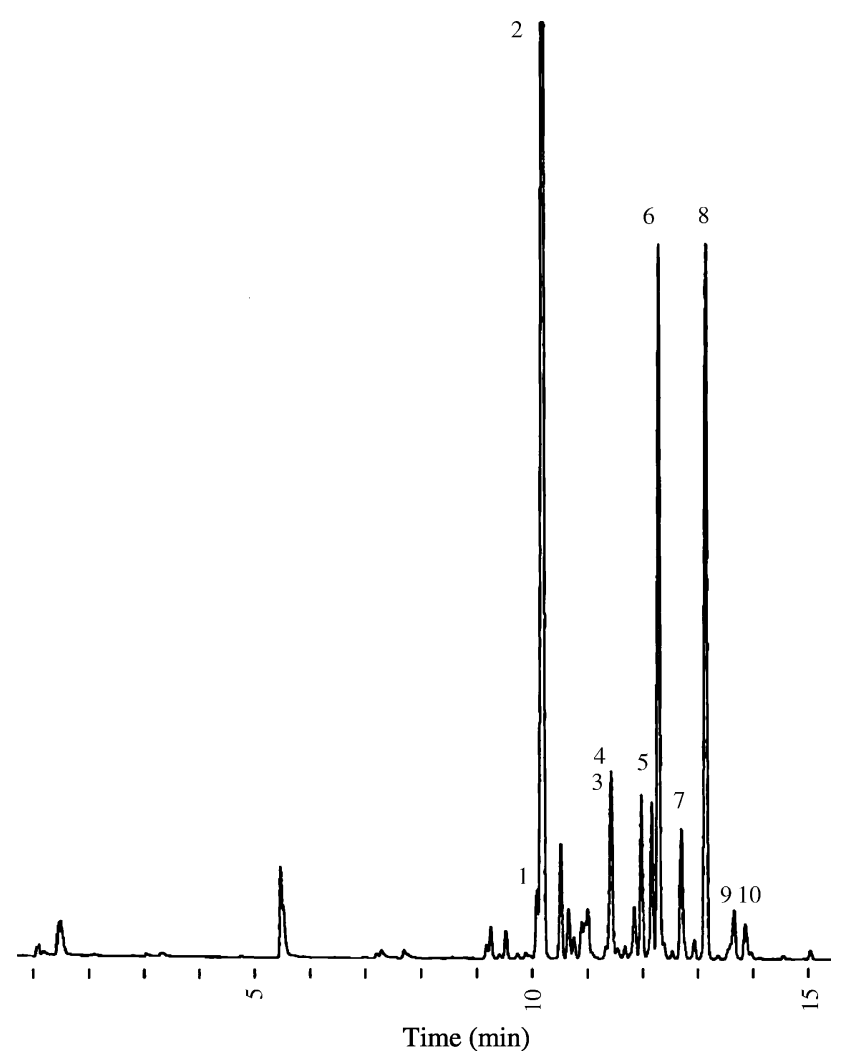

Fig. 1. Typical chromatogram of the volatile fraction emitted by phloem samples of $P$. halepensis detected by GC-FID using a DB5 column and SPME extraction. Peak identification: 1, $\alpha$-thujene; 2, $\alpha$-pinene; 3, fenchene; 4, camphene; 5 , sabinene; $6, \beta$-pinene; 7 , myrcene; $8, \delta$-3-carene; $9, \alpha$-terpinene $+p$-cymene; 10 , limonene.

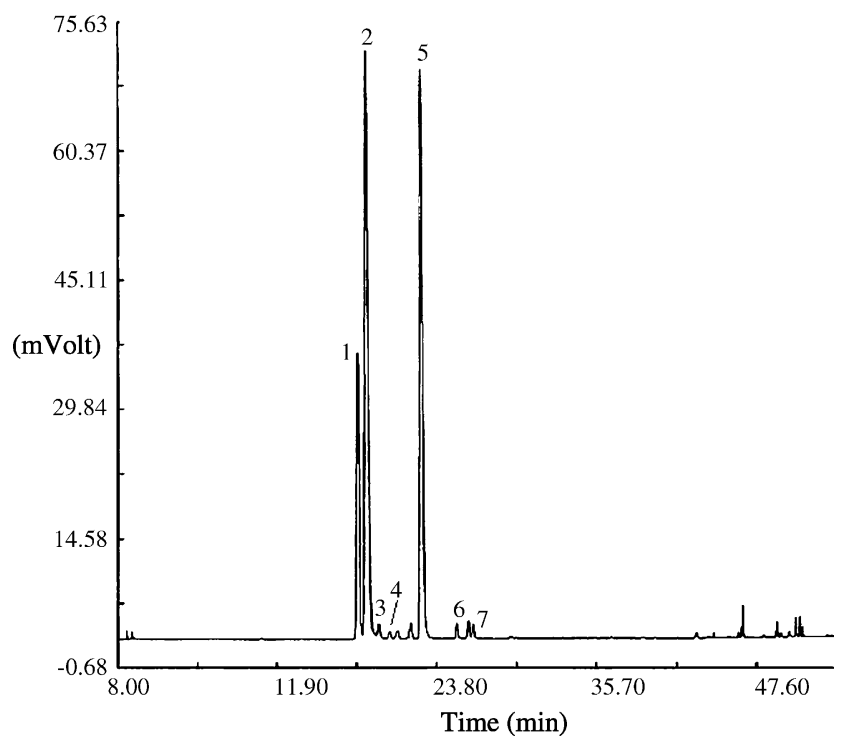

Fig. 2. GC profile of chiral monoterpenes of the phloem volatile fraction of $P$. sylvestris detected by FID, using a tailor made chiral column. Peak identification: $1,(-)-\alpha$-pinene; $2,(+)-\alpha$-pinene; $3,(+)-\beta$-pinene; $4,(-)-\beta$-pinene; 5 , $\delta$-3-carene; $6,(-)$-limonene; 7, (+)-limonene. 
Table 2

Monoterpene composition of the Pinus species studied, using non-enantiomeric separation, calculated based on relative area percentages

\begin{tabular}{|c|c|c|c|c|c|c|c|c|}
\hline \multirow[t]{2}{*}{ Monoterpenes } & \multicolumn{2}{|c|}{ P. pinaster $(N=2)$} & \multicolumn{2}{|c|}{ P. sylvestris $(N=5)$} & \multicolumn{2}{|c|}{ P. pinea $(N=5)$} & \multicolumn{2}{|c|}{ P. halepensis $(N=7)$} \\
\hline & $\begin{array}{l}\text { Relative area } \\
\text { mean }\end{array}$ & $\begin{array}{l}\text { Standard } \\
\text { deviation }(\%)\end{array}$ & $\begin{array}{l}\text { Relative area } \\
\text { mean }\end{array}$ & $\begin{array}{l}\text { Standard } \\
\text { deviation }(\%)\end{array}$ & $\begin{array}{l}\text { Relative area } \\
\text { mean }\end{array}$ & $\begin{array}{l}\text { Standard } \\
\text { deviation }(\%)\end{array}$ & $\begin{array}{l}\text { Relative area } \\
\text { mean }\end{array}$ & $\begin{array}{l}\text { Standard } \\
\text { deviation }(\%)\end{array}$ \\
\hline$\alpha$-Thujene & 0 & 0 & 0 & & 0 & 0 & 2.229 & 1.725 \\
\hline$\alpha$-Pinene & 51.574 & 8.065 & 50.968 & 14.635 & 8.101 & 6.8613 & 33.577 & 18.045 \\
\hline Camphene & 0.965 & 1.364 & 0.000 & 0.000 & 0.000 & 0.000 & 1.350 & 1.508 \\
\hline Sabinene & 0.000 & 0.000 & 0.000 & 0.000 & 0.357 & 0.958 & 3.600 & 2.549 \\
\hline$\beta$-Pinene & 30.126 & 4.208 & 38.503 & 11.689 & 7.565 & 5.877 & 25.419 & 20.189 \\
\hline Myrcene & 3.483 & 1.084 & 0.224 & 0.601 & 9.973 & 13.834 & 7.091 & 11.099 \\
\hline 8-3-Carene & 8.625 & 12.198 & 1.020 & 1.004 & 3.364 & 3.216 & 6.338 & 9.468 \\
\hline \multicolumn{9}{|l|}{$\alpha$-Terpinene } \\
\hline$p$-Cymene & 1.812 & 0.142 & 4.044 & 1.957 & 2.017 & 3.234 & 18.326 & 21.015 \\
\hline Limonene & 3.415 & 2.231 & 5.240 & 4.852 & 68.623 & 27.852 & 2.071 & 2.9725 \\
\hline
\end{tabular}

Table 3

Enantiomeric monoterpene composition of the Pinus species studied, using enantiomeric separation, calculated based on relative area percentages

\begin{tabular}{|c|c|c|c|c|c|c|c|c|}
\hline \multirow[t]{2}{*}{ Monoterpenes } & \multicolumn{2}{|c|}{ P. pinaster $(N=2)$} & \multicolumn{2}{|c|}{ P. sylvestris $(N=5)$} & \multicolumn{2}{|c|}{ P. pinea $(N=5)$} & \multicolumn{2}{|c|}{ P. halepensis $(N=7)$} \\
\hline & $\begin{array}{l}\text { Relative area } \\
\text { mean }\end{array}$ & $\begin{array}{l}\text { Standard } \\
\text { deviation }(\%)\end{array}$ & $\begin{array}{l}\text { Relative area } \\
\text { mean }\end{array}$ & $\begin{array}{l}\text { Standard } \\
\text { deviation }(\%)\end{array}$ & $\begin{array}{l}\text { Relative area } \\
\text { mean }\end{array}$ & $\begin{array}{l}\text { Standard } \\
\text { deviation }(\%)\end{array}$ & $\begin{array}{l}\text { Relative area } \\
\text { mean }\end{array}$ & $\begin{array}{l}\text { Standard } \\
\text { deviation (\%) }\end{array}$ \\
\hline$(-)$ - $\alpha$-Pinene & 1.487 & 1.758 & 42.335 & 11.945 & 0 & 0 & 3.974 & 1.271 \\
\hline$(+)-\alpha$-Pinene & 58.100 & 33.942 & 48.720 & 10.507 & 3.506 & 1.636 & 37.793 & 20.800 \\
\hline$(+)-\beta$-Pinene & 2.623 & 3.709 & 0.840 & 0.325 & 1.094 & 1.001 & 39.603 & 24.032 \\
\hline$(-)$ - $\beta$-Pinene & 4.184 & 5.917 & 0.584 & 0.201 & 4.109 & 5.626 & 0.129 & 0.239 \\
\hline$\delta$-3-carene & 2.742 & 2.436 & 70.134 & 11.411 & 2.259 & 2.123 & 0.419 & 0.396 \\
\hline (-)-Limonene & 12.251 & 8.533 & 0.642 & 0.255 & 0.688 & 0.093 & 9.756 & 14.438 \\
\hline (+)-Limonene & 18.857 & 19.978 & 3.412 & 3.493 & 88.344 & 10.142 & 8.325 & 15.264 \\
\hline
\end{tabular}

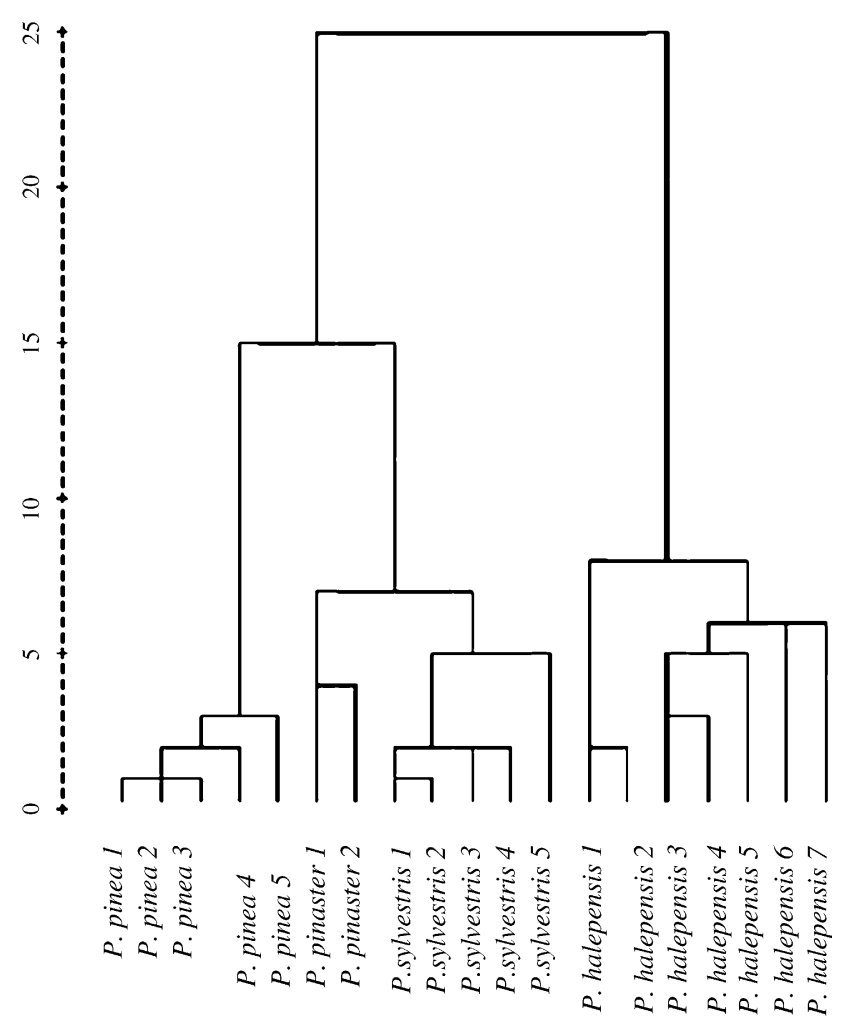

Fig. 3. Dendogram using Ward's method for hierarchical cluster analysis. Pine species were grouped using non-chiral volatile concentrations only.
As reported by Sjodin et al. [8] and by Gomes da Silva et al. [16], it is possible to discriminate Pinus species by analyzing tissues, other than phloem, of trees of this genus, based only on the quantitative enantiomeric composition of the samples. PC analysis was performed using only the results obtained with the chiral column, since it was not possible to normalize the monoterpene data.

Since the enantiomers usually have specific biological activities, each one has to be considered as two separated constituents. For this reason, principal component analysis was performed using the enantiomeric compositions, given as total area percentages, for the monoterpenic compounds identified (Table 3). The three principal components explained $85.78 \%$ of the total variance with the first factor scoring $43.8 \%$ (Table 4).

Table 4

Percentage of the total variance explained by PC analysis, referring to the enantiomeric monoterpene composition of the Pinus species studied

\begin{tabular}{llc}
\hline Components & \multicolumn{2}{l}{ Initial Eigenvalues } \\
\cline { 2 - 3 } & \% of Variance & \% Cumulative \\
\hline 1 & 43.837 & 43.837 \\
2 & 25.491 & 69.327 \\
3 & 16.430 & 85.757 \\
4 & 12.811 & 98.569 \\
5 & 1.431 & 100.000 \\
\hline
\end{tabular}

Three main components were extracted. 

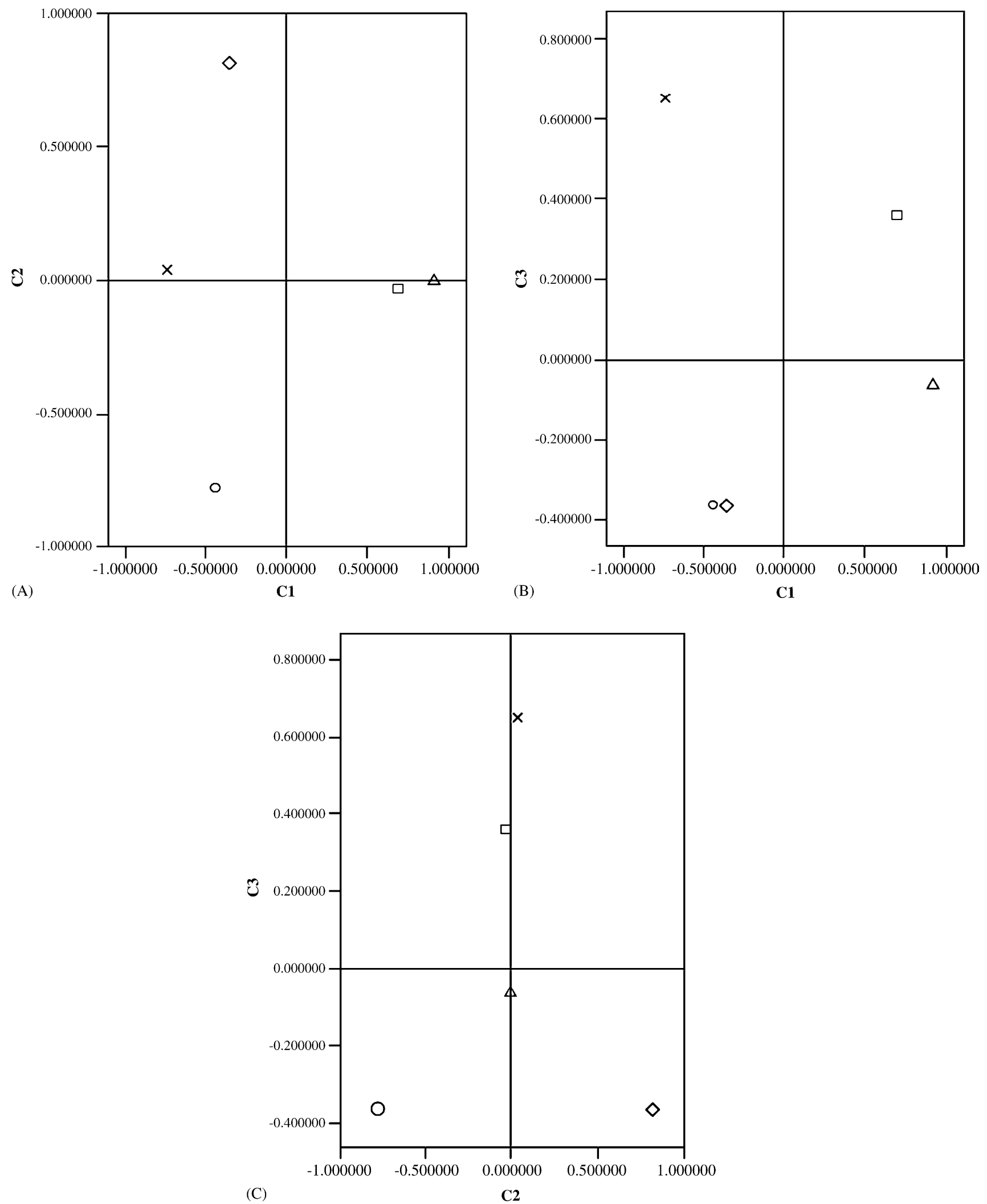

Fig. 4. Component plot of PC analysis performed using the enantiomeric fraction of Pinus spp. phloems. The three components extracted explain $85.76 \%$ of the sample variability: (A) component 1 vs. component 2 ; (B) component 1 vs. component 3 ; (C) component 2 vs. component 3 . Key: [X] (+)- $\alpha$-pinene; $(\bigcirc)(-)$ - $\alpha$-pinene; $(\diamond)(+)$ - $\beta$-pinene; $(\square)(-)-\beta$-pinene; $(\triangle)(+)$-limonene. 


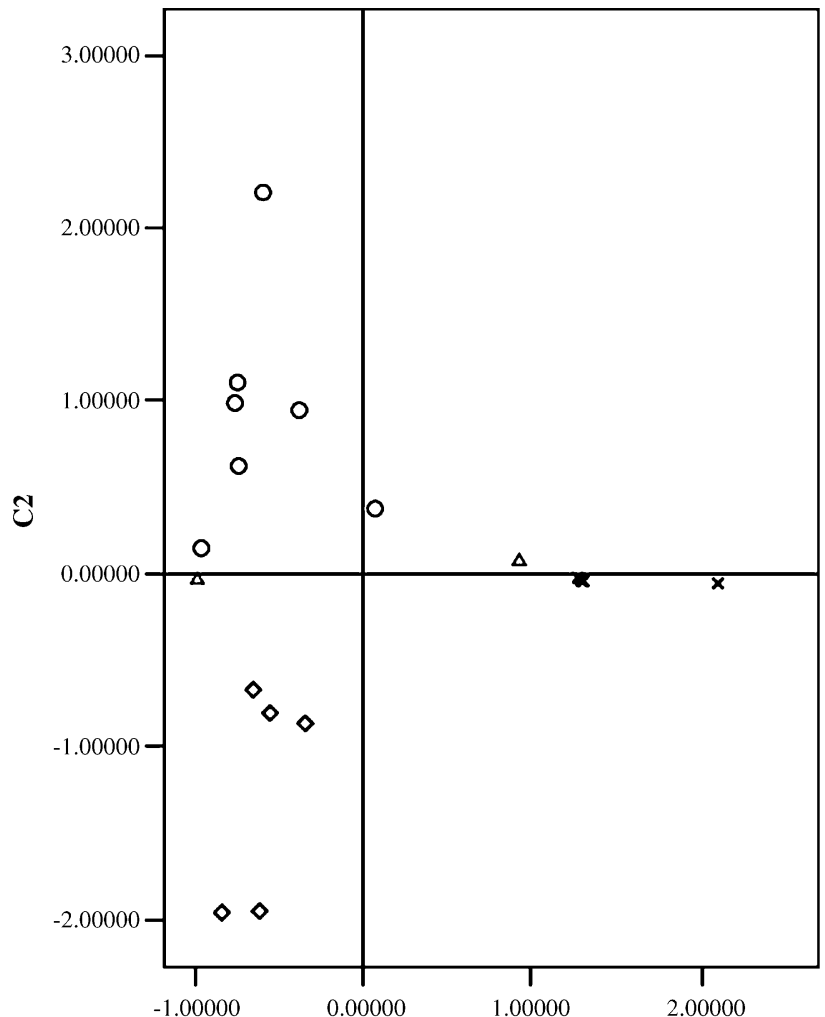

(A)

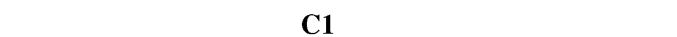

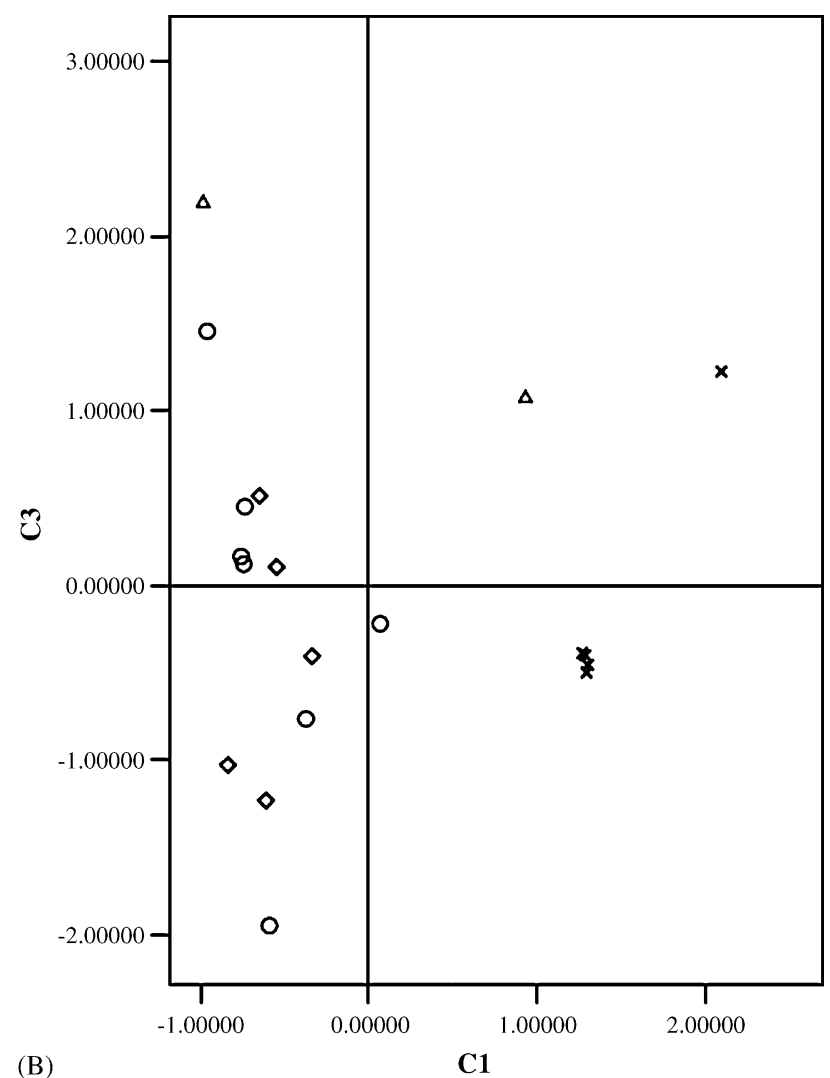

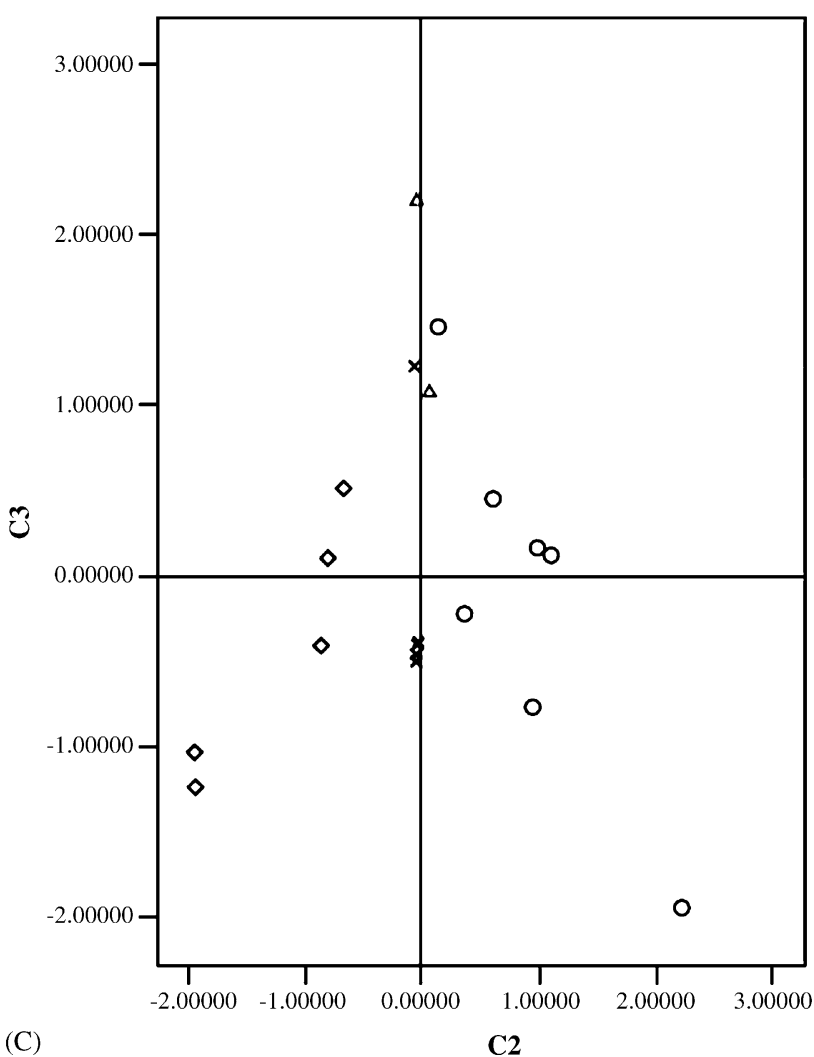

Fig. 5. Scatter-plots of the PC analysis performed using the enantiomeric fraction of Pinus spp. phloems. Three components were extracted: (A) factor 1 vs. factor 2; (B) factor 1 vs. factor 3 ; (C) factor 2 vs. factor 3. Key: $(\diamond)$ P. sylvestris; $(\bigcirc)$ P. halepensis; $(\triangle)$ P. pinaster; $(\times)$ P. pinea. 
The first component is explained by the enantiomers (+)limonene and $(-)-\beta$-pinene versus $(+)-\alpha$-pinene, while the second component is defined by $(+)-\beta$-pinene versus $(-)-\alpha$-pinene. Finally, the third component is characterized by $(+)-\alpha-$ pinene (Fig. 4). PC analysis results, illustrated by Figs. 4 and 5 , show that the discrimination of $P$. pinea is strongly influenced by the contents of $(+)$-limonene and $(-)-\beta$-pinene. $(+)-$ $\beta$-pinene and $(-)-\alpha$-pinene contents discriminate between $P$. halepensis and $P$. sylvestris, respectively. Finally, $P$. pinaster is discriminated based on the contents of $(+)-\alpha$-pinene. Unpublished results (Vasconcelos, in preparation) showed that Tomicus spp. in Portugal preferably attack $P$. pinaster in comparison to other native and exotic pine species. Thus, variations encountered among Pinus species, regarding phloem monoterpene emissions, are of significance considering the selection and colonization processes for insects such as bark beetles.

These results are in accordance with Shaw's morphological classification of the genus Pinus which separates $P$. pinea (Subsection Parapinaster), from the other three species (Subsection Pinaster). This last subsection is further separated into the groups of Laraciones (P. sylvestris) and Insignes (P. pinaster and $P$. halepensis).

Gomes da Silva et al. [16], using needle samples, discriminated 10 pine species based on the enantiomeric contents: (-)- $\beta$-pinene and (+)-limonene for $P$. pinaster; (-)limonene for $P$. pinea; $\alpha$-pinene and (+)- $\beta$-pinene for both $P$. sylvestris and $P$. halepensis. Our results, using phloem samples, revealed a different pattern. This apparent contradiction is explained by authors like Sjodin et al. [8], Pureswaran et al. [9] and Harfouche et al. [17]. The first author emphasized the importance of specifying the plant tissue sampled, since volatile analysis strongly depend on this factor. All authors report large variations in the relative amounts of the volatile components, between and within trees, of the same species.

The distinction between volatile emissions from different tree organs or tissues provides an important cue to decode the mechanism of host selection taking place by different species, or by different stages of the same species, feeding on different parts of the plant. This is the case of Tomicus sp. which feeds on pine needles during a period of the adult stage, before attacking the trunks for breeding. Therefore, the distinction between volatile emissions from different tree organs provides an important cue to decode the mechanism of host selection taking place in different phases of its life cycle.

\section{Conclusions}

Our results indicate that it is possible to discriminate pine species based on monoterpene emissions from phloem samples, using HS-SPME extraction followed by GC and GC-MS analysis.

P. pinea appears to be the most cohesive group of the four species studied, a conclusion which can be derived both from the cluster and PC analysis. The enantiomers emission pattern was different from those obtained for other tissues of Pinus trees. We were able to discriminate $P$. pinea based on the emissions of both (+)-limonene and (-)- $\beta$-pinene, and $P$. pinaster based on $(+)-\alpha$-pinene emissions. Finally, the distinction between $P$. sylvestris and $P$. halepensis was made based on the contents of $(+)-\beta$-pinene and $(-)-\alpha$-pinene.

The fact that the enantiomeric discrimination achieved reflects Shaw's morphological classification of the genus Pinus is an encouraging result leading to further research.

\section{Acknowledgements}

This work was financed by projects POCTI/AGG/47275/02 and EU-PROMOTH (QLRT-2001-00852). The authors are grateful to Professor Dr. Susana Barreiros research team, DQ, FCT, New University of Lisbon, for logistic support with chiral analysis.

\section{References}

[1] T.D. Paine, K.F. Raffa, T.C. Harrington, Annu. Rev. Entomol. 42 (1997) 179.

[2] J.A. Byers, J. Lofqvist, F. Schylter, G. Bergstrom, Naturwissenschaften 72 (1985) 324.

[3] A.E. Santoro, M.J. Lombardero, M.P.J. Ayres, J. Forest Ecol. Manag. 144 (2001) 245.

[4] A.A. Kennedy, D.G. McCullough, Environ. Entomol. 31 (2002) 261.

[5] I. Amezaga, C. Garbisu, Environ. Entomol. 29 (2000) 1011.

[6] S. Trapp, R. Croteau, Annu. Rev. Plant Physiol. Plant Mol. Biol. 52 (2001) 689

[7] T. Norin, Pure Appl. Chem. 11 (1996) 2043.

[8] K. Sjodin, M. Persson, A. Borg-Karlson, T. Norin, Phytochemistry 41 (1996) 439.

[9] D.S. Pureswaram, R. Gries, J.H. Borden, Biochem. Syst. Ecol. 32 (2004) 1109.

[10] P. Tammela, M. Nygren, I. Laakso, A. Hopia, H. Vuorela, R. Hiltunen, Flavour Fragr. J. 18 (2003) 290.

[11] L. Dormont, A. Roquest, C. Malosse, Phytochemistry 49 (1998) 1269.

[12] E. Silvestrini, M. Michelozzi, T. Skroppa, E. Brancaleoni, P. Ciccioli, J. Chromatogr. A 1034 (2004) 183.

[13] R. Slimestad, Biochem. Syst. Ecol. 31 (2003) 1247.

[14] R. Mumm, K. Scharank, R. Wegener, S. Shulz, M. Hilker, J. Chem. Ecol. 29 (2003) 1235 .

[15] R. Mumm, T. Tiemann, S. Shulz, M. Hilker, Phytochemistry 65 (2004) 3221.

[16] M.D.R. Gomes da Silva, E.P. Mateus, J. Munhá, A. Drazyk, M.H. Farrall, M.R. Paiva, H.J. Chaves das Neves, A. Monsandl, Chromatographia 53 (2001) 412

[17] A. Harfouche, W. Boujada, M. Allam, O. Belhou, A. Merazga, Silvae Genet. 52 (2003) 5.

[18] G.K. Girisha, L.M. Condron, P.W. Clinton, M.R. Davis, Forest Ecol. Manag. 179 (2003) 169

[19] W. Oleszec, A. Stochmal, P. Karolewski, A. Simonet, F.A. Macias, A. Tava, Biochem. Syst. Ecol. 30 (2002) 1011.

[20] G. Vazquez, G. Antorrena, J. González, S. Freire, Bioresourse Technol. 51 (1995) 83

[21] G.R. Shaw, Genus Pinus, Riverside Press, Cambridge, 1914.

[22] J.G. Lee, C.G. Lee, J.J. Kwag, A.J. Buglass, G.H. Lee, J. Chromatogr. A 1089 (2005) 227.

[23] A.M. Manninen, S. Tarharnen, M. Vuorinen, P. Kainulainen, J. Chem. Ecol. 28 (2002) 211

[24] M. Idzojtic, D. Kajba, J. Franjié, Biochem. Syst. Ecol. 33 (2005) 427. 
[25] R.D. Burdon, An Introduction to Pines of Silvicultural Importance, CABI Publishing, Wallingford, Oxon, UK, 2002, p. x-xxi.

[26] P. Baradat, A. Marpeau-Bezard, Le pin maritime Pinus pinaster Ait: biologie et génétique des terpènes pour la connaissance et l'amélioration de l'espèce, Ph.D. Thesis, University of Bordeaux I, 1988.
[27] N. Bahrman, M. Zivy, C. Damerval, P. Baradat, Theor. Appl. Genet. 88 (1994) 407.

[28] C. Burban, R. Petit, Mol. Ecol. 12 (2003) 1487.

[29] A.F. Lagalante, M.E. Montgomery, J. Agric. Food Chem. 51 (2003) 2115. 